\title{
Editorial
}

\section{Open up the lung and keep the lung open}

\author{
B. Lachmann \\ Department of Anesthesiology, Erasmus University Rotterdam, The Netherlands
}

Since its introduction into clinical use more than 40 years ago artificial ventilation has proven to be a life-saving method of therapy in intensive care. Yet, it has remained a topic of much discussion and controversy because artificial ventilation involves a disturbance to normal respiratory and cardiovascular function.

It is an established fact that artifical ventilation, especially with large tidal volumes and high peak inspiratory pressures, leads to a decrease in lung compliance and dysfunction of gas exchange. Of even greater importance is the realization that ventilation itself can lead to formation of atelectasis, pulmonary edema, pneumonitis and fibrosis (for review see $[1-4]$ ); that is why the adult respiratory distress syndrome (ARDS) may be, in part, a product of our therapy - rather than the progression of the underlying disease.

To date no adequate explanation of the pathophysiologic basis of these changes caused by artificial ventilation has been documented. The main contributing factors which emerge from almost all the above-mentioned references seem to be the ventilatory modes which fail to prevent partial (or complete) end-expiratory lung collapse combined with high peak inspiratory pressures.

In this issue Sjöstrand's group, using an animal model of ARDS induced by surfactant depletion, applied five established ventilator modes, adjusting either volume or pressure at preset frequencies to keep end-expiratory alveolar pressure at about $16 \mathrm{cmH}_{2} \mathrm{O}$ and $\mathrm{PaCO}_{2}$ constant $( \pm 4 \mathrm{kPa})$. From their study the following three remarkable results emerge:

1. To open up partially collapsed lungs ventilated in their control mode, a peak pressure of $55 \mathrm{cmH}_{2} \mathrm{O}$ (= opening pressure) in combination with an end-expiratory alveolar pressure of about $16 \mathrm{~cm} \mathrm{H}_{2} \mathrm{O}$, resulting in a pressure amplitude of approximately $40 \mathrm{cmH}_{2} \mathrm{O}$, had to be applied for 5-10 min.

2. After opening the lungs $\left(\mathrm{PaO}_{2}>50 \mathrm{kPa}\right)$ they could then be adequately ventilated $\left(\mathrm{PaO}_{2}\right.$ and $\mathrm{PaCO}_{2}$ remained stable) with pressure amplitudes of only 16 to $23 \mathrm{cmH}_{2} \mathrm{O}$ in those ventilator modes which created intrinsic PEEP.
3. In the volume controlled mode, with an external PEEP of $8 \mathrm{cmH}_{2} \mathrm{O}$, a pressure amplitude of almost twice that required by modes creating internal PEEP was necessary for adequate ventilation and even then the lungs could not be kept completely open $\left(\mathrm{PaO}_{2}\right.$ about $\left.40 \mathrm{kPa}\right)$.

\section{Why is it so important to ventilate lungs with as small as possible pressure amplitude?}

More than twenty years ago Mead et al. stated that: "at a transpulmonary pressure of $30 \mathrm{cmH}_{2} \mathrm{O}$, the pressure tending to expand an atelectatic region surrounded by a fully expanded lung would be approximately $140 \mathrm{cmH}_{2} \mathrm{O}$ " [5]. Such forces may well be the major cause of structural damage (especially to bronchiolar epithelium, alveolar epithelium and capillary endothelium) and may not only be the basis for formation of hyaline membranes but may also cause the release of mediators from the disrupted parenchyma - triggering the pathophysiological mechanisms of ARDS [6].

During ventilation of patients with ARDS, who almost always have atelectatic lung regions, pressure differences of $30 \mathrm{cmH}_{2} \mathrm{O}$ or higher are quite common. We have to understand, however, that it is not the $30 \mathrm{cmH}_{2} \mathrm{O}$ pressure difference that damage the lungs but rather the resulting shear forces of more than $140 \mathrm{cmH}_{2} \mathrm{O}$ which are responsible for the barotrauma.

Sjöstrand's group does not present morphological data, but from other experiments related to different modes of artifical ventilation in ARDS lungs (see referred reviews) it was clearly demonstrated that lungs ventilated with modes which did not prevent end-expiratory alveolar collapse, thus creating shear forces, showed more severe morphologic damage (and lower arterial $\mathrm{PaO}_{2}$ ) compared to modes which kept the entire lungs open during the whole respiratory cycle.

It must be concluded that in order to prevent lung damage due to high shear forces between open and closed lung units only ventilation modes which result in the smallest possible pressure amplitude should be used. 
Why is it important to open up the lung and keep it open?

As shown in the results from Sjöstrand's group, if one opens the lungs (by applying a peak inspiratory pressure of $55 \mathrm{~cm} \mathrm{H}_{2} \mathrm{O}$ with an end-expiratory alveolar pressure of $16 \mathrm{cmH}_{2} \mathrm{O}$ for about $10 \mathrm{~min}$ ) only about $20 \mathrm{cmH}_{2} \mathrm{O}$ (range $16-23 \mathrm{cmH}_{2} \mathrm{O}$ ) pressure amplitude is required in all three ventilatory modes which create an intrinsic PEEP to achieve optimal gas exchange in animals suffering from severe ARDS (this raises the question whether one should disconnect patients from the ventilator for routine bronchial toilet and thus allow total lung collapse). This is one of the most important findings from Sjöstrand's group and confirms earlier experimental and clinical data showing that if the right modes of ventilation are chosen - dangerous high shear forces can be avoided [1].

The LaPlace law $(\mathbf{P}=2 \gamma / \mathrm{r}$, where $\mathbf{P}=$ pressure to stabilize a bubble/alveolus; $\gamma=$ surface tension at the air-liquid interface; $r=$ radius of the bubble/alveolus) may offer an explanation why surfactant-depleted ARDS-like lungs with a high and constant surface tension at the airliquid interface could be adequately ventilated with a pressure amplitude of only $20 \mathrm{cmH}_{2} \mathrm{O}$ (which is half the pressure necessary to open up the lung).

Since the critical opening pressure is inversely proportional to alveolar unit size, it follows that progressive recruitment of air spaces requires a continuously increasing pressure during inflation which translates to high peak inspiratory pressure. The pressure necessary to induce volume changes depends on the initial radius. In other words, to get a certain volume change in larger alveoli, the necessary pressure changes are much smaller compared to alveoli which are collapsed or have a lower volume. It can further be derived from the law of LaPlace that the pressure necessary to keep the alveoli open is smaller at a high FRC level. Therefore, the PEEP necessary to stabilize the end-expiratory volume can be minimized if the lungs are totally opened to an FRC level of a healthy lung.

Another reason why the lung should be kept open is the fact that under certain circumstances artificial ventilation affects the pulmonary surfactant system. In normal healthy lungs, during end-expiration the surfactant molecules are compressed on the small alveolar area (leading to a low surface tension or a high surface pressure) thus preventing the alveoli from collapse. If the surface of the alveolus becomes smaller than the total surface of the surfactant molecules, the molecules are squeezed out of the surface and forced towards the airways and thus lost for the alveoli. During the following inflation of alveoli, the surface is replenished with surfactant molecules that were in the hypophase. During the next expiration, the same mechanism continues to work and again surfactant molecules are forced into the airways; this is a continuing cycle [7]. With large tidal volume and/or high rates, surfactant molecules are lost into the airways rather rapidly, as demonstrated by Faridy [8].

This mechanism explain how loss of surfactant by artifical ventilation can be caused by the rhythmic compres- sion (expiration) and decompression (inspiration) of the alveolar lining, especially when the compression is far below (or extremely below if alveolar collapse occurs) the static state of the surfactant layer, which is normally equal to or just above the FRC level [9]. Thus to prevent loss of surfactant by artificial ventilation one should maintain aeration of as large parts of the lung as possible without allowing either hyperdistention or lung collapse.

Keeping the lung open by the appropriate ventilatory modes not only prevents lung damage due to high shear forces, but may also prevent alveolar flooding (i. e. preventing alveolar edema) [10]. In general, alveolar flooding will not occur as long as the negative force in the pulmonary interstitium exceeds the pressure gradient generated by surface tension in the alveolar air-liquid interface. Since the pressure gradient is inversely related to the radius of the alveolar curvature there is, for each combination of interstitial resorptive force and average surface tension, a critical value for surface tension and alveolar radius below which alveolar flooding occurs. In other words a disturbed surfactant system, which in itself leads to alveolar collapse together with smaller alveoli, promote intra-alveolar lung edema.

\section{Why may intrinsic PEEP at pressure controlled ventilation be superior to external PEEP at volume controlled ventilation?}

In an ARDS lung there is non-homogencous distribution of damage over the whole lung. If one applies an external (static) PEEP to a patient with ARDS at volume controlled ventilation with a frequency of $10-15 / \mathrm{min}$ the following changes may be observed:

1. The set PEEP will only balance the increased retractive forces of parts of the damaged lung so that only these parts of the lung will not collapse during the expiratory phase and thus gas exchange will continue during the whole respiratory cycle leading to improved blood gases. 2. The applied external PEEP, however, will not be sufficient to keep all parts of the lungs open. Highly damaged lung regions will be reaerated only at the end of the inspiratory phase; due to the high intra-alveolar pressure at end-inspiration, perfusion will be decreased limiting the contribution of these lung regions to gas exchange.

3. There may also be some healthy regions of the lungs for which the applied external PEEP already leads to capillary compression and a ventilation/perfusion mismatching. This will be even more prominent during the inspiratory phase, causing a dramatic over-distension of these parts.

This may be the scenario for volume controlled PEEP ventilation as it is used in clinical routine. One has to point out, however, that if one does not consider high peak airway pressures as causing lung damage almost every stiff lung can be kept open by a large external PEEP - as is also shown in Sjöstrand's paper.

In contrast, at pressure controlled ventilation if the pre-set peak inspiratory pressure is set to a value which just compensates for the retractive forces of the whole lung, dangerous over-distension of the alveoli can never 
occur. If one then either increases the $I / E$ ratio at a constant frequency, or increases the frequency at a constant I/E ratio (or both) to establish an expiratory time which will be too short to allow emptying of the lung to the ambient pressure, an intrinsic PEEP will be created. If one chooses the absolute time of the expiratory phase so short that also the stiffest parts of the lung have no time for collapse, the lungs will be kept open and can then be ventilated with a significantly smaller pressure amplitude compared to volume controlled PEEP ventilation.

It should be stressed, however, that one should never try to get intrinsic PEEP with volume controlled ventilation, due to the danger of a permanent increase of lung volume resulting finally in barotrauma. In other words, intrinsic PEEP at volume controlled ventilation should be considered as a professional error.

Another interesting finding of the study is that if one just balances the retractive forces by the right pre-set peak pressures at pressure controlled ventilation in combination with proper fluid management this mode will not lead to additional cardiocirculatory depression compared with volume controlled PEEP ventilation.

In summary, the results presented by Sjöstrand's group provide a rationale for optimal ventilator mode which produce minimal pressure swings during the ventilatory cycle and keep the lung volume equal to or just above the FRC level - this to prevent a significant depletion of surface active material. If one follows this concept which, in fact, is not new [1] and if it is once proven to be the right way for any form of respiratory support, the diversity of ventilatory modes may no longer cause confusion for the practitioner as there is only one rational concept to preserve lung integrity: open up the whole lung and keep it totally open, with the least influence on the cardiocirculatory system.

\section{References}

1. Lachmann B, Danzmann E, Haendly B, Jonson B (1982) Ventilator settings and gas exchange in respiratory distress syndrome. In: Prakash O (ed) Applied physiology in clinical respiratory care. Nijhoff, The Hague, pp 141-176

2. Froese AB (1989) Role of lung volume in lung injury: HFO in the atelectasis-prone lung. Acta Anaesthesiol Scand 33 [Suppl 90] $126-130$

3. Sykes MK (1991) Does mechanical ventilation damage the lung? Acta Anaesthesiol Scand 35 [Suppl]:35-39

4. Hickling KG (1990) Ventilatory management of ARDS: can it affect the outcome? Intensive Care Med 16:219-226

5. Mead J, Takishima T, Leith D (1970) Stress distribution in lungs: a model of pulmonary elasticity. J Appl Physiol 28:596-608

6. Spragg RG, Smith RM (1991) Biology of acute lung injury. In: Crystal RG, West JB et al (eds) The lung: scientific foundation. Raven Press, New York, pp 2003-2017

7. Bos JAH, Lachmann B (1992) Effects of artificial ventilation on surfactant function. In: Rügheimer $\mathrm{E}$ (ed) New aspects on respiratory failure. Springer, Berlin Heidelberg New York, pp 194-208

8. Faridy EE (1976) Effect of distension on release of surfactant in excised dogs' lungs. Respir Physiol 27:99-114

9. Benzer H (1969) Respiratorbeatmung und Oberflächenspannung in der Lunge. In: Frey R, Kern F, Mayrhofer O (eds) Anaesthesiologie und Wiederbelebung. Springer, Berlin Heidelberg New York, p 38

10. Guyton AC, Moffat DS, Adair TA (1980) Role of alveolar surface tension in transepithelial movement of fluid. In: Robertson B, Van Golde LMG, Batenburg JJ (eds) Pulmonary surfactant. Elsevier, Amsterdam, pp 171-185

Prof. Dr. Dr. B. Lachmann

Department of Anesthesiology (Room EE2393)

Erasmus University Rotterdam

Postbox 1738

NL-3000 DR Rotterdam

The Netherlands 